\title{
EXCLUSÃO DO SUJEITO NEGRO E A NEGAÇÃO DE RAÇA NA PRODUÇÃO ACADÊMICA EM RELAÇÕES INTERNACIONAIS NO BRASIL
}

\author{
ANANDA VILELA DA SILVA OLIVEIRA \\ Doutoranda em Relações Internacionais pelo Instituto de Relações Internacionais da \\ Pontifícia Universidade Católica do Rio de Janeiro - IRI/PUC-Rio. \\ E-mail: ananda.vilela@hotmail
}

\begin{abstract}
RESUMO: Um sistema político forjado na lógica da branquitude e o racismo à brasileira impõem classificações de superioridade e inferioridade nas hierarquias sociais. Com isso, sujeitos negros, definidos a partir de discursos científicos racistas são supostamente irracionais e desprovidos de inteligência, enquanto sujeitos brancos colhem os privilégios adquiridos por meio da exploração indébita da mão de obra escravizada. Pensar a disciplina de Relações Internacionais no Brasil é entender que esse contexto de exploração, apropriação e extermínio da população negra no país permeiam os debates acerca do internacional neste campo do saber, mesmo que silenciados por mecanismos de exclusão de produção de conhecimento na ciência moderna. Sob esta égide, este artigo busca entender como a categoria raça, e o contexto racial no Brasil atravessam a construção do campo das RI no país. Na intenção de expandir os debates historiográficos acerca da institucionalização de cursos de pós-graduação em RI no Brasil, faz-se uso de uma abordagem decolonial em perspectiva afrodiaspórica. Para tal, empreende-se um levantamento bibliográfico sobre RI no país, tangenciando categorias como colonialidade, racismo e epistemicídio como ferramentas analíticas que possibilitam a leitura da colonialidade do conhecimento no ensino e pesquisa das RI.
\end{abstract}

PALAVRAS-CHAVE: Exclusão do negro; produção de conhecimento; Teoria das Relações Internacionais.

\section{THE EXCLUSION OF THE BLACK SUBJECT AND THE NEGATION OF RACE IN THE ACADEMIC PRODUCTION IN INTERNATIONAL RELATIONS IN BRAZIL}

\begin{abstract}
A political system forged in the logic of whiteness and Brazilian racism imposes classifications of superiority and inferiority in social hierarchies. As such, black subjects, defined from racist scientific discourses, are irrational and unintelligent, while white subjects reap the privileges acquired through the improper exploitation of enslaved labor. To think about the discipline of International Relations in Brazil is to understand that this context of exploitation, appropriation and extermination of the black population in the country permeates debates about the international in this field of knowledge, even if silenced through the mechanisms of exclusion of knowledge production in science. Modern. Under this umbrella, this article seeks to understand how the category race and racial context in Brazil cross the construction of the IR field in the country. In order to expand the historiographical debates about the institutionalization of postgraduate courses in IR in Brazil, a decolonial approach in afrodiasporic perspective is used. To this end, a bibliographic survey on IR in the country is undertaken, tangential categories such as coloniality, racism and epistemicide as
\end{abstract}


analytical tools that enable the reading of the coloniality of knowledge in the teaching and research of IR.

KEYWORDS: Black exclusion; knowledge production; Theory of International Relations.

\section{Introdução}

O conhecimento científico que os negros necessitam é aquele que os ajude a formular teoricamente - de forma sistemática e consistente - sua existência de quase 500 anos de opressão.

Abdias do Nascimento.

Há muitos trabalhos sobre a historiografia do curso de Relações Internacionais no Brasil (MIYAMOTO, 1999; 2003; HERZ, 2002; SANTOS, 2005; JULIÃO, 2009; 2012; FERREIRA, 2015; TOSTES, SILVA, 2017). Cada um, à sua maneira, coloca o surgimento das $\mathrm{RI}$, como disciplina, em um contexto de demanda política interna por maior internacionalização do país. Destacam-se, nesse período, as conquistas nacionais no sistema internacional, sua importância enquanto ator periférico das relações internacionais e a ampliação do interesse da opinião pública nessas questões. Em poucas palavras, o internacional, no contexto imediato aos primeiros cursos de Rl do país, passava a ter maior relevância nas políticas domésticas e isso demandava um curso especializado em análises do sistema internacional e as relações entre Estados (FERREIRA, 2015).

Contudo, essas análises não levam em conta dois fatores importantes do contexto histórico do país: a ditadura militar e o racismo inerente à sociedade brasileira. Nesta, embora atualmente $54 \%$ da população declare-se negra ${ }^{1}$, tal parcela permanece subrepresentada nas instâncias políticas, econômicas, sociais, culturais e acadêmicas. Segundo Thula Pires (2018, p. 1056), "desde a invasão europeia e consolidação do projeto colonial em terras brasileiras, a raça determina a hierarquia a partir da qual se organizam relações intersubjetivas e, principalmente, institucionais". Nesse sentido, atentar-se para as relações de raça no contexto da criação do curso de RI no Brasil oferece outro olhar sobrea construção e consolidação da disciplina. Esta que, seguindo moldes norte-americanos, mostra-se

\footnotetext{
${ }^{1}$ IBGE. População chega a 205,5 milhões, com menos brancos e mais pardos e pretos. Disponível em <https://agenciadenoticias.ibge.gov.br/agencia-noticias/2012-agencia-de-noticias/noticias/18282populacao-chega-a-205-5-milhoes-com-menos-brancos-e-mais-pardos-e-pretos $>$. Acesso em 16 de maio de 2019.
} 
um reduto branco, resultando em um curso com professores "brancos que ensinam em departamentos brancos e publicam em jornais brancos" (VITALIS, 2015, p. 13).

Entendendo que toda produção de conhecimento se dá de maneira situada, localizada (HARAWAY, 1995) e a partir de necessidades e fomentos políticos, considero necessária a contextualização da institucionalização da área de Relações Internacionais no Brasil. Indo além das muitas obras que contextualizam essa construção do campo, busco demonstrar através de uma perspectiva afrodiaspórica o que foi silenciado e/ou negado enquanto relevante na consolidação do campo. De acordo com Nascimento (1980, p. 160) "o racismo constitui a espinha dorsal psicosóciocultural que faz da sociedade convencional brasileira uma entidade intrinsecamente preconceituosa e discriminadora dos descendentes afro-negros". Portanto, analisar a construção da disciplina sem considerar sua composição branca (VITALIS, 2015) oferece uma análise enviesada dela, encobrindo a branquitude como raça hegemônica e não nomeada no curso.

Dessa forma, volto a atenção para o contexto histórico-político-socialeconômico imediato à institucionalização dos primeiros cursos em RI no Brasil, que propiciaram seu fortalecimento e afastaram suas proposições das demandas de mais da metade da população brasileira, a saber, a população negra. Com isso em mente, empreendo uma revisão bibliográfica acerca da institucionalização no curso no país, já amplamente conhecida entre os teóricos de RI no Brasil, bem como uma ampliação dos debates sobre raça neste campo de estudos. Para tal, este artigo é dividido em três seções distintas além desta breve introdução. A primeira seção se debruça sobre as conceituações acerca de raça, racismo e branquitude compreendendo que essas categorias e conceitos permeiam as relações sociais da sociedade brasileira como um todo e, portanto, a institucionalização do curso no país. A segunda seção trabalha as ideias de colonialidade e epistemicídio, uma vez que essas categorias são base para a construção do conhecimento moderno tal como entendemos hoje. A terceira seção aborda especificamente a construção do campo de RI no Brasil, colocando-a no contexto da ditadura militar brasileira, que mesmo cerceando debates autônomos dentro desta área do saber, se beneficiou do silêncio em torno das questões de raça e racismo por parte da elite que compunha 
esse curso. Com uma leitura afrodiaspórica, me atento às exclusões do curso e a perpetuação de práticas educacionais excludentes à população negra.

\section{Raça: marcador de diferenças e possibilidades}

No Brasil, estruturado por um sistema político forjado na branquitude, os efeitos da violência física e epistêmica perpetrada contra sujeitas e sujeitos negros são diferentes de outros contextos históricos. Aqui, a humanidade de povos negros, sequestrados da África e trazidos para o continente, foi negada. O processo de escravização de povos negros os definiu como objetos e propriedade de senhores brancos (NASCIMENTO, 2016). Na mesma linha de argumentação de Frantz Fanon (1979), povos negros foram alocados na zona do não ser, enquanto sujeitas e sujeitos brancos compõem a zona do ser. Fanon explica que o mundo colonizado é um mundo maniqueísta. Nele, colonos e colonizados são separados na zona do ser e na zona do não ser. Na zona do ser, o opressor faz existir o domínio, a pilhagem, a exploração (FANON, 1979), nela há saúde, riqueza, segurança. Já na zona do não ser só há violência, espoliação, a insegurança é regra, não exceção (FANON, 1979). Com esse olhar, o mundo maniqueísta é pensado a partir dos termos da zona do ser, mas aplicados em qualquer contexto. Em outras palavras, existe a imposição de um imaginário que não condiz com a realidade da zona do não ser. Em contexto brasileiro, a branquitude como um sistema político (BENTO, 2002) forja realidades degradantes ao povo negro.

Com isso, sujeitas e sujeitos brancos, em detrimento de povos negros e indígenas, foram posicionados em altos níveis de hierarquia em uma escala de classificação de povos, devido às estruturas moderna-coloniais de governar que foram naturalizados por classificações e hierarquizações de humanidade, inteligência e moralidade que possibilitam a alguns chegar a patamares inalcançáveis para outros (BENTO, 2002). Essa branquitude, então, vai além de uma carga identitária, se transformando em normas, padrões e pactos que sustentam um sistema de supremacia branca (BENTO, 2002). Logo, é sob a lente da branquitude que se constrói a visão que é perpetuado sobre o povo negro na 
sociedade brasileira, no sistema educacional e nas RI como disciplina de forma particular.

O estudos de branquitude no Brasil, elaborados por teóricos afrodiaspóricos como Maria Aparecida da Silva Bento, que no contexto da psicologia traz contribuições para os estudos críticos da branquitude, apresenta a branquitude como "construção social e história, [que] possibilita aos indivíduos se situarem no interior de uma formação coletiva, sólida, uma comunidade de negação, que nega e exclui da realidade o que não interessa" (BENTO, 2014, p. 18). A branquitude, então, se mostra como uma norma na sociedade, um ponto de vista no qual as pessoas brancas olham a si mesmas e aos outros. Assim, a branquitude faz referência a práticas que, mesmo que não marcadas ou nomeadas, estão ocultas e atuando nas relações sociais (BENTO, 2014).

Nesses termos, cria-se um padrão de civilização que consolida normas para a sociedade, estabelece as posições que cada classe social/raça pode ser colocada. Uma maneira de posicionar esses sujeitos foi por meio do estabelecimento do conhecimento científico como única possibilidade de verdade. Nesse sentido, nas incessantes tentativas do Ocidente de universalizar seu próprio saber, René Descartes propôs a divisão mente e corpo no sujeito. Com essa segmentação o teórico pretendia substituir o conhecimento teológico, abandonado pelo movimento de secularização iluminista, apresentando o homem como capaz de produzir um conhecimento universal tal como um olho de Deus, que tudo vê, tudo produz, tudo explica (GROSFOGUEL, 2016). Como nos informa Grosfoguel (2016), para defender a universalidade do conhecimento humano Descartes parte de dois argumentos diferentes, um ontológico e um epistemológico.

Ontologicamente, Descartes propôs um dualismo entre mente e corpo, em que mente é uma substância diferente daquilo que a contém (GROSFOGUEL, 2016). Sem esse dualismo ontológico, seria impossível afirmar um conhecimento universal, posto que a mente estaria localizada num corpo, num lugar específico em um tempo particular. Já o segundo argumento é de ordem epistemológica e surge da afirmação de que o "Eu" alcança seu conhecimento por meio de um monólogo interno do sujeito com ele próprio, chamado método do solipsismo (GROSFOGUEL, 2016). Com essa acepção, exclui-se a ideia de um saber dialógico e, portanto, 
social, vide que as relações sociais não estão perdidas no tempo e no espaço, mas bem localizadas.

Dessas afirmações, questiona-se: quem é o sujeito universal cartesiano? De acordo com Enrique Dussel (2008), Descartes em nenhum momento se referiu a um sujeito colonizado, um corpo negro ou indígena, ou mesmo à mulher. Dessa forma, obtém-se que este sujeito universal é o homem branco europeu, excluindo do âmbito do dualismo ontológico, corpo e mente, todos os "Outros" desse sujeito. Afinal, como afirma Mbembe (2014, p. 27), "o hemisfério ocidental considerava-se o centro do globo, o país natal da razão, da vida universal e a verdade da Humanidade". Entendendo que a criação de teorias parte da construção social do discurso, podese inferir que a divisão mente e corpo do sujeito cartesiano foi projetada de forma a justificar a realidade social de exclusão desses "Outros" da vivência social.

Nesse contexto sócio-político da branquitude, a negação do negro como um sujeito moderno advém da racialização e subjugação de seu corpo dentro do quadro do colonialismo. Para Frantz Fanon (2008), raça é o adjetivo dado ao ressentimento amargo, ao irrepreensível desejo de vingança daqueles que lutaram contra a sujeição e foram obrigados a sofrer no contexto de escravidão e sequestro de povos africanos de seu continente para terras longínquas. Por conseguinte, defendo aqui a ideia compartilhada por autores decoloniais latino-americanos: raça, como construção social, está no centro de um sistema hierárquico que produz diferenças (QUIJANO, 2000). Conforme Mbembe (2014, p. 70), "a raça é uma das matériasprimas com as quais fabricamos a diferença e o excedente, isto é, uma espécie de vida que pode ser gasta sem reservas". Essas diferenças, por sua vez, criam e reproduzem representações do negro, que se apresentam como subsídios para a sua exclusão das esferas sociais brancas. A classificação por raça permite localizar os corpos que são estigmatizados, excluídos, derrotados, desqualificados, internados ou expulsos (MBEMBE, 2014) e os que são colocados em altas posições nas hierarquias sociais. Assim, ainda que uma invenção de elites racistas, a raça enquanto fator social e simbólico.

Assim, conforme Fanon (2008), o complexo de inferiorização de sujeitos negros obedece a um duplo processo: inicia-se com uma desvantagem econômica; e, atinge uma interiorização, "uma epidermização dessa inferioridade" (2008, p. 28 
grifo nosso). Contudo, movimentos sociais e intelectuais negros buscam maneiras diversas de contrapor a essas práticas normativas e esse sistema político excludente. Para isso, o Mbembe, inspirado por Fanon, propõe um gesto de autodeterminação e reconhecimento de si mesmo, da identidade negra como propulsora de conhecimentos específicos, de saberes localizados, um "modo de presença em si, olhar interior e utopia crítica" (MBEMBE, 2014, p. 58). Nesse momento, o negro passa a dizer sobre si mesmo, a encontrar sua história e ancestralidade, a reunir fragmentos dispersos de sua comunidade em todo o mundo. Portanto, enquanto em um primeiro texto, a razão negra seria uma "consciência ocidental do Negro", a segunda proposição se refere a uma "consciência negra do Negro" (MBEMBE, 2014), um ato de reconhecimento e reinserção na história, agora pelos próprios termos.

Nessa perspectiva, Mbembe dissolve o ideário de dualismo ontológico do sujeito cartesiano. Para o autor, é nesse contexto de declaração da identidade negra que a razão negra remete à indissociação entre o instinto animal e a ratio do negro (MBEMBE, 2014). Se o sujeito cartesiano empreende a tentativa de oposição à animalidade, o sujeito negro não o faz. Assim, o que está em jogo na discussão acerca da razão negra são as disputas sobre as regras de definição do Negro, sua identidade, seu espírito animal e as condições em que essa ratio pode penetrar nessa animalidade (MBEMBE, 2014).

Contudo, a reivindicação de reconhecimento da capacidade racional de sujeitos negros e sua potencialidade de produção de conhecimento, não sendo apenas objeto dele, não se dá de maneira fácil. Como demonstra Fanon (2008), no interior da sociedade ocidental e racista, a aceitação e respeito à diversidade ontológica e epistemológica é ainda uma pedra angular nas relações sociais. Uma vez que a branquitude estrutura a sociedade ocidental, a identificação do povo negro com sua própria comunidade ocorre de maneira lenta e processual, dificultando o sentimento de comunidade e coletivização de sujeitos negros. São nessas tentativas de demolição do mito sobre o homem negro, de sua incapacidade e animalidade, que o negro busca ocupar os espaços aos quais Ihe foram negados. 


\section{Colonialidade e epistemicídio na ciência moderna}

As tentativas de descolonizar o pensamento e transversalizar raça como estruturantes das relações sociais entre povos e culturas, bem como 0 descentramento do conhecimento moderno surgem desde proposições das teorias pós-coloniais. Entretanto, como afirma Mignolo (1998), o pós-colonialismo ainda mantem um certo compromisso narrativo euro-estadunidenses. Com isso, na medida em que não há uma ruptura com discursos e narrativas acabam por reforçar as bases epistemológicas hegemônicas. Neste contexto de críticas ao eurocentrismo, teóricos como como Ramón Grosfoguel, Walter Mignolo, Enrique Dussel, Arturo Escobar, Aníbal Quijano, Santiago Castro-Gómez, Nelson Maldonado-Torres formaram o Grupo Modernidade/Colonialidade (BALLESTRIN, 2013). Alguns desses autores, apesar de se inspirarem em teorias europeias, se esforçam por romper com o discurso hegemônico, propiciando um viés crítico latino-americano buscam se distanciar das amarras do conhecimento ocidental.

Consoante com estudos pós-coloniais, os teóricos decoloniais denunciam o provincianismo da produção de conhecimento. Segundo suas premissas, a estrutura epistêmica contemporânea baseada em homens ocidentais advém de apenas cinco países: França, Inglaterra, Alemanha, Estados Unidos e Itália (GROSFOGUEL, 2016). Nas Relações Internacionais a mesma questão é abordada, incluindo neste grupo de países teóricos australianos que se traduziu na Escola Inglesa de RI, que, em menor medida, contribuem para a disciplina (JONES, 2006). Logo, isso demonstra que a produção de conhecimento está demarcada geograficamente, indo contra a própria pretensão de ciência universal não situada.

Com efeito, a geopolítica do conhecimento, a inscrição geográfica do pensamento (MALDONADO-TORRES, 2008; MIGNOLO, 2002), tende a estabelecer um lócus de enunciação, que determina um dos critérios de autorização e legitimação da produção de saber. Em outras palavras, somente os saberes produzidos desde e por Europa e Estados Unidos serão legitimados, enquanto tantos outros serão invisibilizados. Assim, essa geopolítica se organiza negando a diversificação epistemológica de diferentes culturas através da história, por meio de imposições coloniais de conhecimentos alheios as realidades sociais fora da Europa 
ou Estados Unidos (MIGNOLO, 2002). Se dá, então, a exclusão, a desautorização, a deslegitimação e a apropriação da diversidade de saberes em nome de uma ciência universal construída por poucos países.

Nessa esteira, Castro-Gómez nos orienta que a colonialidade do poder de Quijano (2000) tende a ampliar e corrigir "o conceito foucaultiano de 'poder disciplinar', ao mostrar que os dispositivos pan-óticos erigidos pelo Estado moderno inscrevem-se numa estrutura mais ampla, de caráter mundial, configurada pela relação colonial entre centros e periferias devido à expansão europeia" (2005, p. 87).. De acordo Maldonado-Torres (2008), a colonialidade do poder é um padrão de dominação específico que articula raça e capitalismo, é "um modelo de poder especificamente moderno que interliga a formação racial, o controle do trabalho, o estado e a produção de conhecimento" (MALDONADO-TORRES, 2008, p. 88). A colonialidade, como defende Mignolo (2010), é uma estrutura de níveis entrelaçados composta pelo controle da economia, controle da autoridade, controle da natureza e dos recursos naturais, controle do gênero e da sexualidade e controle da subjetividade e do conhecimento.

O controle da produção de conhecimento estabelece a colonialidade do saber. Como defende Edgardo Lander (2000), a colonialidade do saber, por si, não tem somente um caráter eurocêntrico, mas se articula com as formas de domínio colonial e neocolonial dos conhecimentos das Ciências Sociais e das humanidades. Essa articulação perpassa os anos, e ainda performa um papel relevante para o domínio imperial/neocolonial. A colonialidade do saber em um contexto político social de branquitude, em conjunto com um racismo estrutural a sociedade brasileira, se traduz um racismo epistêmico, que passa a proibir a produção autônoma de conhecimento (GROSFOGUEL, 2016). Contudo, sujeitos negros produzem conhecimento, bem como qualquer ser humano. Esses conhecimentos são obliterados pelos processos de produção dominantes, em nome da universalidade de saberes provincianos, propostos por poucos, cinco países (GROSFOGUEL, 2016). A essa negação de epistemologias, que serve aos interesses dessa sociedade dominante, Boaventura de Sousa Santos chama epistemicídio, "a supressão dos conhecimentos locais perpetrada por um conhecimento alienígena" (SANTOS e MENEZES, 2010, p. 17). Essa violência 
epistêmica, também denunciada por Castro-Gomez (2005) e outros teóricos decoloniais, culminou na redução da diversidade epistemológica do mundo, a favor de um conhecimento universal, que não respeitou as condições históricas sob as quais foi introduzido, nem os conhecimentos outros que suprimiu.

A busca pela universalidade do sistema de conhecimento ocidental, então, é levada a cabo via supressão da diversidade de conhecimentos ao longo da história, principalmente, mas não somente, durante o contexto colonial e pós-colonial da América Latina. O projeto de modernidade instaurou a necessidade de validação dos saberes desde o reforço das formas de poder e dominação colonial. A classificação e categorização dos negros e indígenas como inferiores e incapazes de produzir conhecimento afirmou a capacidade do "Eu" europeu de falar por eles, munidos de uma autoridade e legitimidade científica (SMITH, 2012). Segundo Linda Tuhiwai Smith (2012), o contexto de invalidação de conhecimentos acarretou na consolidação de saberes, sistemas de categorização, tecnologias e modos de organização social registrados sobre os povos nativos, tanto de América quanto te África, como propriedade do conhecimento do arquivo cultural ocidental. Logo, a construção de um aparato científico que coloca o nativo como objeto do saber do homem branco, e o reforço de sua autoridade como único produtor possível desse conhecimento. Observo, então, a colonialidade do saber em sua funcionalidade principal: colonizar as mentes dos colonizados, de modo a enxergarem apenas essa opção de conhecimento como viável.

No cenário de destituição da humanidade de sujeitos negros e negação de sua racionalidade, os conhecimentos e culturas africanas são obliterados e apagados, deslegitimados e desvalorizados. Como afirma Nascimento (2016), existem obstáculos teóricos e práticos que impedem a afirmação dos afrobrasileiros, e dos negros em qualquer contexto, como elementos constitutivos e construtores da vida cultural e social brasileira. Na mesma linha, Smith (2012) reforça a ideia de que as abordagens ocidentais se veem como as únicas possíveis, corretas, as únicas capazes de dar algum sentido a realidade, as únicas aptas à produção cultural. Isso se explica pelas formas de abordar os indígenas e negros como imersos em uma noção de superioridade civilizacional ocidental, também pela ambição europeia, e estadunidense num contexto atual, de impor seu ideal de 
progresso e racionalidade a todos os seres humanos da terra, um destino manifesto de levar a civilização - ocidental - a todos os cantos do mundo. Aos olhos dessa cultura dominante, a criatividade cultural do "outro", indígena e negro, não passa de uma curiosidade etnográfica, e sem valor artístico: "para se aproximar da 'categoria' da 'arte sagrada' do ocidente, o artista negro teria de esvaziar sua arte do seu conteúdo africano e seguir modelos branco-europeus" (NASCIMENTO, 2016, p. posição 2391).

Nesta conjuntura, Nascimento (2016), acerca do contexto afro-brasileiro, denuncia que os brancos, o Ocidente no geral, além dos órgãos de poder - governo, leis, capitais, forças armadas, polícia - possuem poderosos implementos de controle social e cultural: o sistema educativo, comunicação de massa e produção literária. Então, "todos esses instrumentos estão a serviços dos interesses das classes no poder [os brancos] e são usados para destruir o negro como pessoa e como criador e condutor da própria cultura" (NASCIMENTO, 2016, p. posição 1951). De acordo com Ramón Grosfoguel (2016) essa situação se dá desde a criação de um aparato institucional/acadêmico que serve aos interesses brancos, negando a capacidade intelectual dos sujeitos negros de produzir conhecimento.

A exclusão do negro dos âmbitos de construção de saber é histórica. A negação da razão negra, que sim, existe, é flagrante. O projeto de conhecimento científico da modernidade objetificou os corpos negros, negando sua capacidade de autoridade e de busca pelo saber, produzindo conhecimentos que não atendem aos interesses e demandas de povos negros, reduzindo seu ser a um corpo biológico, irracional, animalizado. Nesse contexto, faz-se urgente o descentramento das ciências modernas e o reconhecimento da contribuição de conhecimentos múltiplos para a sua construção.

De acordo com Silvio Almeida (2018, p. 37), "em uma sociedade em que o racismo está presente na vida cotidiana, as instituições que não tratarem de maneira ativa e como um problema a desigualdade racial irão facilmente reproduzir as práticas racistas já tidas como 'normais' em toda a sociedade". Portanto, é esse racismo institucional e estrutural que consolida as posições dos negros em baixos níveis de escolaridade e, como consequência, com baixos níveis salariais e sendo mão de obra barata. Não é à toa que as universidades estão cheias de brancos, 
enquanto os negros estão no chão de fábrica, nas favelas, nas prisões, ou seja, na zona do não ser, conforme proposta por Fanon (1979).

Dessa forma, faz-se necessário a leitura das relações sociais além da forma como este conhecimento ocidental e colonial determinou. A partir disso, Mbembe (2014) defende que apresentar o mundo não reduzido à Europa auxilia na reabilitação da singularidade e da diferença. Nessa esteira, na próxima seção abordo a formação da academia de Relações Internacionais no Brasil e sua institucionalização em torno da colonialidade do poder no contexto da ditadura militar. Além disso, sua consolidação epistemológica importou conceitos estadunidenses de análise em detrimento de conhecimentos afrodiaspóricos potentes para a internacionalização do Brasil.

\section{A academia de Relações Internacionais no Brasil}

A desumanização de sujeitos negros no Brasil foi colocada em prática no contexto do colonialismo português no país por meio da escravização de povos africanos sequestrados de suas terras e trazido para este lado do atlântico. Nessa esteira, povos foram dizimados, conhecimentos obliterados e uma nova cultura e modo de vida foram impostos. Aqui, então, percebe-se a operação da colonialidade do ser (MALDONADO-TORRES, 2008), relacionando o colonialismo à não existência do "outro", que toma o sujeito negro como carente de ontologia, de essência (FANON, 2008).

Isto posto, é importante salientar a reiteração do colonialismo em corpos negros, mesmo no período pós-independência, portanto, a colonialidade. O Brasil foi o último país na América a abolir a escravidão, demonstrando o reforço da colonialidade na elite brasileira, que se beneficiava socialmente, politicamente e economicamente dessa escravização e desumanização de sujeitos negros. A inferiorização de povos negros, já apontada por Fanon (2008), continuou no Brasil mesmo no período pós-escravidão, uma vez que a lei de abolição não veio acompanhada de assistências e garantias que protegessem os então exescravizados no sistema de trabalho livre (FERNANDES, 2008). Como aponta Bento 
(2002), o pacto narcísico entre brancos fortalece suas posições na sociedade enquanto subordina o povo negro em torno de suas próprias convicções.

Nos termos desta estrutura supremacista branca, do pacto narcísico da branquitude e do racismo/sexismo inerentes dessa sociedade, houve um processo maciço de embranquecimento da população negra em busca de um padrão euro e brancocêntrico. Como efeito, processos de genocídio físico e cultural e a violência sexual contra as mulheres negras como parte dessas práticas genocidas deu ao Brasil um caráter multirracial. Neste contexto, o regime militar no Brasil marcou um período de ampla disseminação da violência com justificativas de proteção do país contra ameaça comunista. Se no período pós-independência brasileira o medo branco consistia no receio de que os então escravizados se unissem contra as forças dominantes impulsionados pela Revolução Haitiana (GOMES, 2019), durante a ditadura o medo era que o país se tornasse uma nova Cuba no continente. Com isso, a repressão e perseguição a agrupamentos suspeitos pelas autoridades era constante. Atrelado a esse fato, a branquitude como estrutura normativa na realidade brasileira (BENTO, 2002) transformava sujeitos negros em inimigos com base em suas ditas propensões violentas e/ou revolucionárias. Dessa forma, sujeitos negros como Abdias do Nascimento e Maria Beatriz do Nascimento, e tantos outros com menor lastro cultural, eram acusados de subversão da ordem estatal, associação com Embaixadas africanas e apropriação de discurso racial de organizações ditas terroristas (PIRES, 2018).

Todo e qualquer aquilombamento negro era veementemente perseguido pelo Estado. De acordo com Abdias do Nascimento (1980) não houve só quilombos, como formas associativas de resistência ilegais no interior das florestas, mas também quilombos legalizados com fins religiosos, recreativos, beneficentes, esportivos ou culturais. Estes quilombos aceitos seriam "associações, irmandades, confrarias, clubes, grêmios, terreiros, centros, tendas, afoxés, escolas de samba, gafieiras" (NASCIMENTO, 1980, p. 255), que integravam prática de libertação e comando da própria história. Em contexto ditatorial, essas associações eram perseguidas, alvejadas e exterminadas com a justificativa de desordem social. Entretanto, a verdade é que esses agrupamentos colocavam em risco a falsa ideia de democracia racial internacionalmente disseminada e qualquer movimentação que 
colocasse em risco essa ordem pretendida desde o mito de democracia racial e expusesse as rupturas sociais e raciais no contexto brasileiro eram neutralizadas. Os agrupamentos negros eram perseguidos Brasil afora, o encontro de muitas pessoas negras caracterizaria um movimento político anti-integracionista (PIRES, 2018). Como defende Thula Pires (2018), não só houve uma violência racial sofrida por negras e negros no período de governo militar, mas também uma "repressão orientada a neutralizar os processos de articulação negra" (PIRES, 2018, p. 1062).

A despeito de afirmações em relação a esses agrupamentos, associações negras não consistem em modos de se fechar ao mundo, excluindo brancos de sua composição, mas sim formas de existência e resistência dentro de uma sociedade racista como o Brasil. Portanto, a repressão contra povos negros refletia o racismo estrutural vigente nesta sociedade. Internacionalmente, o mito da democracia racial representava um orgulho nacional, servindo de modelo para o mundo, uma contribuição brasileira como um país de integração e iguais oportunidades de existência (NASCIMENTO, 2016). Essa imagem era justificada principalmente em comparação aos Estados Unidos, onde a segregação racial era legalizada, via leis Jim Crown, ou o apartheid na África do Sul. Satirizando sobre o assunto, Lélia Gonzalez afirma

Racismo? No Brasil? Quem foi que disse? Isso é coisa de americano. Aqui não tem diferença porque todo mundo é brasileiro acima de tudo, graças a Deus. Preto aqui é bem tratado, tem o mesmo direito que a gente tem. Tanto é que, quando se esforça, ele sobe na vida como qualquer um. Conheço um que é médico; educadíssimo, culto, elegante e com umas feições tão finas... Nem parece preto (GONZALEZ, 1984, p. 226).

Gonzalez satiriza aqui o imaginário social da época, que acreditava não haver racismo no Brasil, ou se fazia passar por um país não racista, uma vez que os países aos quais o Brasil era comparado mantinham a segregação por meios jurídicos. Inclusive, Nascimento (1980) defende a tese de que a realidade social brasileira em muito se assemelhava com a sociedade racista estadunidense, com a diferença de que no Brasil havia (e ainda há) uma maioria de descendência africana e seu papel na edificação do Estado brasileiro foi mais intenso do que nos Estados Unidos, principalmente por conta da duração de quase 400 anos de escravidão. 
Com isso em mente, Gonzalez afirma que a sociedade brasileira está permeada pelo que chamou de o racismo por denegação. Denegação se refere a não aceitação de algo que contém em si, não somente a não aceitação, mas a negação de que exista, nega-se que é racista, mesmo que as práticas e relações sociais dessa pessoa digam o contrário (GONZALEZ, 1988). Se nos Estados Unidos havia uma segregação ostensiva, aqui havia uma segregação por denegação (GONZALEZ, 1988).

A despeito do que acontecia em âmbito doméstico, com todo o genocídio físico e cultural da população negra em nome de um padrão brancocêntrico de integração racial, a internacionalização do ideal político de democracia racial no país, forjado para servir a um projeto político de supremacia branca, mantinha a falsa ideia de perfeita harmonia e integração entre povos brancos, negros e indígenas (GONZALEZ, 1988). A construção político-histórica dessa autoimagem brasileira foi exportada e usada para legitimar ideologias de branqueamento para dentro, como extermínio físico, social e cultural de povos negros. O mito de democracia racial, inclusive, foi corroborado com a ratificação de três importantes documentos internacionais no que condiz a discriminação: a Convenção 111 OIT (1958), a Convenção relativa à luta contra a discriminação no ensino (1960 e 1968), e a Convenção internacional sobre a Eliminação de Todas as Formas de Discriminação Racial (1968 e 1969) (PIRES, 2018). Em relação à última convenção, o Brasil usou de seu direito de proibir o acesso aos autos do processo de adesão a convenção a qualquer cidadão que não fosse os representantes do país na ONU (NASCIMENTO, 1980). Dessa informação suspeita-se que o país possa ter aderido à convenção com restrições que permitiriam o contínuo massacre da população negra em território nacional (NASCIMENTO, 1980), que acabaria por quebrar o falso imaginário social internacional de democracia racial brasileira e, por isso, o sigilo do documento.

Ainda, no mesmo período de ratificação destes tratados, o Brasil votava a favor de Portugal, na Assembleia Geral da ONU - especificamente em 1966 - no que condizia a continuação da colonização de países africanos, com a justificativa de que a perda dessas colônias seria de grande impacto econômico para a metrópole (NASCIMENTO, 1980). Neste caso, fica claro como não importava aos 
militares brasileiros no governo as tentativas de independência dos povos negros africanos, tampouco as formas de resistência e emancipação de povos negros no Brasil. Nas palavras de Nascimento, esse posicionamento do Brasil nas votações das resoluções da Assembleia Geral refletiam o "desprezo racista, supremacismo branco, elitismo oficial, plasmando uma irredutível posição de antagonismo do Brasil-dirigente com as aspirações de liberdade e independência dos nossos irmãos do continente" (NASCIMENTO, 1980, p. 191).

Em relação ao apartheid na África do Sul, o Brasil, à época do regime militar, buscava relações com o país segregado em vistas de ter acesso ao urânio de Pretória. Nessa perspectiva, não importava aos militares a intensa segregação racial, extermínio da população negra, exclusão das instâncias de representação e negação à cidadania de sujeitas e sujeitos negros na África do Sul. As incontáveis tentativas de construção de um tratado do Atlântico Sul, entre Argentina, Brasil e África do Sul entre as décadas de 1960 e 1970 (NASCIMENTO, 1980), exemplificam os interesses reais da branquitude brasileira e, mais uma vez, denuncia o racismo velado existente na política tanto interna quanto externa. O urânio de Pretória se mostra aqui como uma moeda de troca nas relações internacionais, em que o Brasil compra às custas do genocídio da população negra dos dois lados do atlântico.

Com efeito, é neste contexto de mito da democracia racial, racismo por denegação, colheita de privilégios materiais e simbólicos na herança social racial e econômica da branquitude (BENTO, 2002) e posicionamento internacional brasileiro contra a descolonização da África e fortalecimento de povos negros ao redor do mundo, que a disciplina de RI no Brasil é cogitada entre as possibilidades de construção de conhecimento no país. Durante a década de 1970 e 1980, os defensores da institucionalização de um campo de estudos focado nas Relações Internacionais afirmavam a necessidade de tal construção calcados na justificativa de que o país despontava como ator internacional relevante no Sistema Internacional e nas relações econômicas internacionais (MIYAMOTO, 2003).

Nesse sentido, a organização do campo era sugerida e fortalecida a partir da confluência dessas áreas que já estavam mais consolidadas academicamente e que produziam análises sobre o internacional que viriam a ser alocadas nos estudos em RI (LAFER, 2018). Em relação a isto, as primeiras gerações dos cursos de pós- 
graduação em RI continham em si uma forte interdisciplinaridade, posto que entre as décadas de 1970 e 2000 existiam apenas dois cursos na área, o que restringia o volume de docentes especializados em RI habilitados a lecionar nesses programas. Assim, os professores que davam aulas nestes cursos advinham principalmente das áreas da Economia, História, Direito e Ciência Política, na quais suas pesquisas tinham alguma proximidade com as RI. Essa confluência de áreas diferentes no campo das RI deu base para os primeiros cursos institucionalizados no país.

A narrativa sobre a construção do curso girava em torno da vinculação dos fundamentos da política externa brasileira e seus interesses desenvolvimentistas durante o período militar (MIYAMOTO, 1999). Como exposto acima, o Brasil, durante as décadas de 1960 e 1970, alinhava sua política externa com Portugal. Com isso, o país posicionava-se contra os movimentos de independência nas colônias portuguesas na África, e tentava, incessantemente, construir a consolidação de um acordo do Atlântico Sul com Argentina e África do Sul, durante o período do apartheid racial (NASCIMENTO, 1980). A criação das RI no Brasil, então, responde a demandas internas do regime militar em tecnicizar e qualificar os estudos que possibilitariam melhor posicionamento do Brasil no sistema internacional. As Rl, como curso, têm conexão com o posicionamento do Brasil em relação aos impasses internacionais relacionados à independência colonial e segregação racial tanto na África do Sul quanto nos Estados Unidos, uma vez que surgiu justamente para fortalecer esse tipo de política.

Isto posto, o primeiro curso de graduação em Relações Internacionais foi criado na Universidade de Brasília (UNB) em 1974. Não à toa, o lugar escolhido para a implantação do primeiro curso tinha intensa ligação com o quadro de decisão da política nacional, os professores e idealizadores da área no contexto brasileiro atuavam tanto no âmbito acadêmico da universidade, como na formação de diplomatas no Instituto Rio Branco (JULIÃO, 2012). Nesse contexto, a matriz de poder que representa a colonialidade do poder fica ainda mais evidente. $O$ controle político que parte do Congresso Nacional, Palácio do Planalto e Itamaraty se liga com a produção de conhecimento acadêmico que serve ao Estado brasileiro. Uma vez que o Estado empreende o genocídio do povo negro e as teorizações 
hegemônicas em RI não se atentam a estas dinâmicas domésticas, os conflitos internos são dissimulados em nome de um Estado unitário e racional externamente.

No regime militar a universidade desempenha um papel estratégico como a representação de um espaço privilegiado de construção do saber. Com um ideário desenvolvimentista voltado para fora, a produção de saber especializado se mostra como um diferencial entre os competidores no mercado internacional. Além disso, a divisão entre a mão de obra pobre e negra e as cabeças pensantes, a elite branca do Estado brasileiro, mostrava-se ainda mais evidente. A representação das forças de poder nesse ambiente e suas respostas a essas correlações de forças faziam da universidade um espaço de legitimação do poder e forças de dominação.

A escolarização de sujeitos negros é deficiente no Brasil desde o período colonial e perpassa os séculos. Através de várias manobras jurídicas e legislativas o acesso de negros a educação foi cerceado de maneira constante desde a primeira república no Brasil. A primeira lei que previa a educação primária gratuita a todos os cidadãos data de 1824, na própria Constituição Imperial (ALMEIDA e SANCHEZ, 2016). Entre as inúmeras reviravoltas legislativas, várias foram as formas de exclusão de sujeitos e sujeitas negras da educação básica, seja por meio da explicita negação desses corpos nas instituições de ensino, como a reforma da instrução primária realizada em 1837 na província do Rio de Janeiro, seja por meio de manobras excludentes, como processos de admissão nas escolas e pagamento de taxas acesso ao ensino, como a reforma Rivadávia Correia, de 1911 (ALMEIDA e SANCHEZ, 2016). Uma vez sem acesso as escolas, por impeditivos estruturais e institucionais, a resistência do povo negro e a busca pela educação formal se deu dentro do próprio movimento negro (PASSOS, 2012). A situação educacional só veio a se transformar e considerar o povo negro a partir do fim do Estado Novo, já na década de 1940, quando os movimentos negros voltaram a se fortalecer com o fim do período ditatorial e, com isso, reivindicar maior acesso à educação (ALMEIDA e SANCHEZ, 2016). Percebe-se aqui o intenso interesse por parte do Estado de cercear qualquer possibilidade de ascensão social do sujeito negro.

Neste artigo essas informações acerca da escolarização de povos negros no Brasil se tornam relevantes na medida em que informam quem eram (e ainda são) os sujeitos que tema acesso à educação superior no país. Uma vez que sujeitas e 
sujeitos negros estão lideram os índices de analfabetismo e evasão escolar, como teriam acesso a produção de conhecimento acadêmico nas universidades? Indo além, como alcançaram as altas hierarquias educacionais relacionadas a pósgraduação? A criação do primeiro curso em RI, em 1974, e seu fortalecimento nos anos posteriores não tinha relação com a necessidade de universalização do ensino no país. Por meio das inúmeras formas de exclusão jurídica de acesso à educação, somente com o fortalecimento dos movimentos negros que as demandas por acesso à educação são parcamente atendidas (ALMEIDA e SANCHEZ, 2016). Dessa forma, infiro aqui que as primeiras gerações de cursos de RI no Brasil, bem como todo o sistema universitário, foram pensadas de brancos para brancos.

Considerando a constituição do sistema de ensino universitário como lócus de poder e negociação e inserida na modernidade, este espaço é permeado tanto pela colonialidade que vai além do colonialismo, se traduzindo na colonialidade das mentes e saberes de sociedades pós-coloniais, quanto pelo racismo/sexismo inerente da sociedade brasileira. Na mesma linha de argumentação, Boaventura de Sousa Santos e Maria Paula Menezes (2010) afirmam que o colonialismo tem uma dimensão de dominação epistemológica que tende a produzir e reproduzir uma relação desigual de saber e poder, que conduz ao epistemicídio de culturas e conhecimentos ancestrais.

Nesses termos, teóricos da área da educação defendem que a universidade se torna, então, parte fundamental da engrenagem de um modo colonial de organização, perpetuando uma hierarquização da produção de conhecimento de intelectuais que contemplam o eurocentrismo (MIRANDA, 2006). É de acordo com isso que Boaventura de Sousa Santos e Naomar de Almeida Filho (2008, p. 63), debatendo a democratização da universidade, afirmam que esta "deve dar uma centralidade muito específica às ações contra a discriminação racial". A universidade, como esse lócus de poder, produz e reproduz sujeitos e subjetividades. A produção de subjetividades imersas em relações de poder no contexto acadêmico se faz por meio de narrativas particulares sobre o indivíduo e a sociedade e auxilia na produção e reprodução de sujeitos, uma vez que corporificam noções particulares de conhecimento (GOMES, 2018). 
A institucionalização de RI no Brasil não está isolada dessa engrenagem, pelo contrário, se alinha a ela na produção de conhecimento e consolidação dos programas de pós-graduação. De acordo com Claudia Miranda (2006), em estudos sobre as narrativas subalternas e políticas de branquidade no contexto acadêmico brasileiro, o ofício da academia fora dos países centrais, euro-estadunidenses, tem como função apoiar a pesquisa do intelectual legitimando narrativas construídas dentro do cânone desejado, pesquisas interessadas e sem qualquer neutralidade. Nesse cenário, os processos de marginalização e tematização de áreas especiais das RI resulta na permanência dos debates hegemônicos no cânone euro estadunidense, não sendo reconhecidos outros interlocutores do internacional como parte desse campo do saber.

No caso das RI, demonstravam como a construção do saber pautaria, justificaria e legitimaria o posicionamento brasileiro no sistema internacional. $O$ controle do conhecimento, como exposto pela colonialidade do poder (MALDONADO-TORRES, 2008), se faz presente não só pela proximidade da UNB com o polo de tomada de decisão no Brasil, mas também com a relação e a presença dessas forças de poder, desses tomadores de decisão no contexto da universidade.

$\mathrm{Na}$ construção da tendência que seria a criação de cursos de RI no Brasil, foi criado em 1979 o segundo núcleo de estudos na área, o Instituto de Relações Internacionais (IRI) da Pontifícia Universidade Católica do Rio de Janeiro (PUC-RIO) (VIGEVANI, THOMAZ e LEITE, 2016). Ao contrário da UNB, o IRI criou-se inicialmente como um espaço de pesquisa em RI. Dessa forma, o mestrado foi criado no instituto em 1987, já o doutorado foi institucionalizado em 2001. Na UNB, o mestrado em RI foi institucionalizado em 1984, enquanto o doutorado em 2002. De 1984 a 2001, os dois institutos de pesquisa eram os únicos a promover o conhecimento na área de RI especificamente. Além destes, a pesquisa de relações internacionais se dava no âmbito das linhas de pesquisa em mestrados e doutorados na área de História, Direito e Economia (MIYAMOTO, 1999; JULIÃO, 2012; VIGEVANI, THOMAZ e LEITE, 2016).

O crescimento do número de cursos no Brasil foi impulsionado em grande parte por medidas político-institucionais de regulação da educação superior em nível 
federal e subnacional (FERREIRA, 2015). Assim, a partir da Lei de Diretrizes e Bases da Educação Nacional, de 1996, a Lei 10.861/2004, que estabeleceu um sistema de avaliação do sistema nacional de educação superior e a Lei 11.096/2005 que instituiu o Programa Universidade para Todos - PROUNI (FERREIRA, 2015), a universidade ganhou outro caráter nos níveis de educação no país. As condições educacionais no Brasil desde 1990, com as inúmeras medidas governamentais de regulação da educação superior resultou em 84 novos cursos de graduação em RI no país entre 2001 e 2015 (FERREIRA, 2015). Esse crescimento, no entanto, enfrentava problemas estruturais no que condizia a falta de professores especializados na área para alcançar a demanda dos novos cursos. Por um tempo, isso se mostrou como um desafio à expansão dos cursos de pós-graduação nessa área, portanto, enquanto os cursos de graduação aumentavam exponencialmente $\mathrm{e}$ demandavam mais profissionais aptos ao ensino, os cursos de pós enfrentavam a falta de docentes especializados neste campo (MIYAMOTO, 2003).

Com o aumento da demanda por docentes e analistas especializados neste campo do saber, além das tendências liberalizantes com o fim da Guerra Fria e a reconstrução política dos países periféricos, o governo federal empreendeu novos financiamentos para a criação de novos programas de pós-graduação na área. Sob o governo de Fernando Henrique Cardoso a Coordenação de Aperfeiçoamento de Pessoal de Nível Superior (CAPES) divulgou o edital San Tiago Dantas, que tinha como objetivo "desenvolver o ensino de pós-graduação em relações internacionais em instituições públicas, formando assim recursos humanos de alto nível, fortalecendo e ampliando programas de pós-graduação existentes e criando novos" (CAPES, [2001] 2008). Esse edital destinou $\mathrm{R} \$ 800$ mil a cada um dos cinco cursos projetos aprovados, sendo eles os programas de pós-graduação em Relações Internacionais da Universidade Estadual Paulista, Universidade de Campinas e PUC-SP (2003), da Universidade Federal Fluminense (UFF) (2008), da Universidade Federal do Rio de Grande do Sul (UFRGS) $(2002)^{2}$ e da UNB (2002), que

\footnotetext{
${ }^{2}$ Destaco que os mestrados em Relações Internacionais da UFF e da UFRGS foram extintos em 2007 e 2011, respectivamente. Ambos, por meio de editais de incentivo governamentais, se transformaram em mestrado em Estudos Estratégicos, mantendo grande parte da grade docente dos cursos anteriormente constituídos.
} 
institucionalizou seu doutorado por meio desse incentivo (VIGEVANI, THOMAZ e LEITE, 2016).

Nesse caso, e no contexto de editais posteriores ${ }^{3}$ de apoio aos programas de pós-graduação em Relações Internacionais (PPGRI), ${ }^{4}$ percebe-se a intenção estatal do fortalecimento da área de Rl como um campo chave para a leitura do internacional em contexto brasileiro. Ainda, vê-se a colaboração de ministérios e agentes políticos no desenvolvimento da área. Assim, para além dos já citados programas, outras universidades como PUC-Minas, Universidade Estadual da Paraíba (UEPB), Universidade do Estado do Rio de Janeiro (UERJ), Universidade Federal de Santa Catarina (UFSC) e Universidade de São Paulo (USP) institucionalizaram seus programas de pós-graduação na área (VIGEVANI, THOMAZ e LEITE, 2016). Atualmente, existem onze PPGRI no Brasil, segundo dados da Plataforma Sucupira (CAPES, 2018), além dos já citados, excluindo os já extintos, existem agora programas na Universidade Federal da Bahia (UFBA), Universidade Federal da Paraíba (UFPB) e Universidade Federal de Uberlândia (UFU). ${ }^{5}$

Insta salientar a constituição desses programas em sua maioria na região sudeste do país, seis (PUC-Rio, PUC-Minas, UNESP, UFU, USP, UERJ), dos onze programas, estão no Sudeste, um no Distrito Federal (UNB), três no Nordeste (UFBA, UEPB e UFBP) e um no Sul (UFSC). Aqui, percebe-se a geopolítica do conhecimento, tal como abordada pelas teorias decoloniais (MALDONADOTORRES, 2008; MIGNOLO, 1996; 2003). Com efeito, a geopolítica do conhecimento, a inscrição geográfica do pensamento (MALDONADO-TORRES, 2008; MIGNOLO, 2002), tende a estabelecer um lócus de enunciação, que determina um dos critérios de autorização e legitimação da produção de saber. Assim, essa geopolítica se organiza a diversificação nas margens, através da história, das diferenças coloniais e imperiais (MIGNOLO, 2002).

\footnotetext{
${ }^{3}$ Edital San Tiago Dantas (2001) e edital Renato Archer (2006), da CAPES; edital Pró-Defesa (2005, 2008 e 2013); edital Pró-Estratégia (2011) (VIGEVANI, THOMAZ e LEITE, 2016).

${ }_{4}^{4}$ Foram considerados aqui somente os programas que se autodenominam explicitamente como programas de pós-graduação em Relações Internacionais.

${ }^{5} \mathrm{O}$ mestrado em Relações Internacionais na Universidade Federal da Integração Latino-Americana (UNILA), não foi contabilizado, uma vez que sua criação data de 2019 , e os dados obtidos são de 2018.
} 
O conhecimento no Brasil é construído desde sua proximidade com as forças dominantes de poder. Assim, não é de se estranhar que a maioria dos programas se encontram no Sudeste, polo econômico, político e industrial do país. A colonialidade do poder é vista mais uma vez, posto que essa região teve vantagens em direção ao desenvolvimento político e econômico desde o período colônia, transformando-se no polo produtivo no país. O Sudeste, como esse polo das relações de poder, colhe os privilégios simbólicos, econômicos, políticos e culturais do colonialismo, que tem como consequência a colonialidade do saber, que acompanha as forças de poder e, no contexto internacional, é produzido um conhecimento desde o eixo euroestadunidense.

O mesmo Estado brasileiro que promoveu e promove o genocídio da população negra em nome do ideal de democracia racial é o Estado que financiou a criação de programas de pós-graduação em RI. Da mesma forma, é o Estado que reivindicava a internacionalização desse ideal, como um Estado unitário, homogêneo e democrático, tal como preconiza as teorias hegemônicas nas RI, como Realismo e Liberalismo. Epistemologicamente, as teorias hegemônicas dão base para imagem que o Brasil intenciona internacionalizar, negando os conflitos e disputas raciais e em torno da falsa democracia racial no interior das fronteiras estatais. Contudo, são esses mesmos conflitos e disputas que permeiam as decisões governamentais, como o apoio do país às práticas coloniais portuguesas, ou a negação de acesso a sujeitos negros à educação desde o nível básico ao universitário, ou a criação de um curso como RI, elitista e branco (VITALIS, 2015), tanto no Brasil como no mundo.

Institucionalmente, observamos a consolidação de um curso permeado pelas estruturas racistas da sociedade brasileira, respondendo e reforçando essa estrutura por meio da colonialidade, branquitude e pacto narcísico. Nos termos do crescimento das universidades no Brasil é difícil quantificar a população negra nesse nível de ensino, uma vez que existe uma dificuldade num contexto maior de dados em relação a escolarização de sujeitas e sujeitos negros com a extinção da classificação por raça nas pesquisas de censo da população. Essa extinção informa muito sobre o ideal de democracia racial presente no Brasil, no qual se não havia dados acerca da diferenciação racial da população e se, como era exportado para o mundo, aqui havia uma integração racial, não seria necessário políticas de igualdade 
social (PASSOS, 2012). Essa realidade só veio mudar a partir de 1987, com a Pesquisa Nacional por Amostra de Domicílios (PNAD), realizada pelo Instituto Brasileiro de Geografia e Estatística, que passou a incluir a classificação racial como critério. Nesta pesquisa os resultados expressavam a desigualdade educacional que infringia os povos negros no país, constatando um "maior índice de analfabetismo, exclusão, evasão e reprovação escolar entre alunos negros do que entre os brancos" (CAVALLEIRO, 2000 apud ALMEIDA e SANCHEZ, 2016). Em 1995, o Relatório do Desenvolvimento Humano do Brasil reforçava as informações da PNAD/1987, afirmando ainda que sujeitas e sujeitos negros possuíam desvantagens no ingresso nas instituições escolares e progressão e conclusão de seus estudos em relação aos brancos (ALMEIDA e SANCHEZ, 2016).

Se a pesquisa de 1987 indicava a extrema desigualdade educacional infringida contra sujeitas e sujeitos negros, fica claro que não eram essas pessoas que tinham acesso ao estudo das RI nessas grandes universidades. Além disso, não há grande expressão de interesse na construção de um perfil para o estudante de RI nas pesquisas da área, seja na graduação ou na pós-graduação pelo menos até 2015. No Brasil, apesar de aproximadamente 55\% (96.795.294) da população se auto declarar preta e parda segundo o IBGE (2017), ${ }^{6}$ no mesmo ano, de acordo com dados do INEP, ${ }^{7}$ apenas 2,6\% (2.689.796) estava matriculada em cursos de graduação no Brasil. Em 2015, segundo mapeamento produzido pela Unesco, o curso de Relações Internacionais, nos anos 2009, 2012 e 2015 - de acordo com os dados informados na conclusão da prova do ENADE - apresenta seus egressos de acordo com as seguintes estatísticas: 72,6\% (12.179 estudantes) auto declarados brancos, 15,6\% (2.617 estudantes) pardos, 3,5\% (588 estudantes) pretos não quilombolas, 2,1\% (352 estudantes) amarelos, 0,3\% (50 estudantes) indígenas e $5,9 \%$ (989 estudantes) que não responderam. ${ }^{8}$

\footnotetext{
${ }^{6}$ IBGE. População chega a 205,5 milhões, com menos brancos e mais pardos e pretos. Disponível em <https://agenciadenoticias.ibge.gov.br/agencia-noticias/2012-agencia-de-noticias/noticias/18282populacao-chega-a-205-5-milhoes-com-menos-brancos-e-mais-pardos-e-pretos $>$. Acesso em 16 de maio de 2019.

7 INEP. Censo de educação superior 2017. Disponível em <http://inep.gov.br/web/guest/sinopsesestatisticas-da-educacao-superior>. Acesso em 16 de maio de 2019.

${ }^{8}$ CNE/UNESCO. O fortalecimento do papel institucional do Conselho Nacionais de Educação no processo de elaboração, aperfeiçoamento e acompanhamento das políticas públicas de educação básica e superior em todas as etapas e modalidade de educação e ensino: Documento Técnico referente ao Produto 2 do Projeto CNE/UNESCO 914/BRZ1042.3 - Contrato AS-379/2017. 2017.
} 
Esses dados podem refletir várias dinâmicas excludentes, seja uma defasagem do ensino nos níveis fundamental e médio, que impede sujeitas e sujeitos negros de alcançarem o nível superior; seja a imposição de um conteúdo que não abarca a realidade negra; seja a imposição de uma língua estrangeira que não é acessível a esses estudantes etc. Além disso, as informações refletem as relações sociais de uma sociedade racista que impede por meios políticos, sociais, econômicos, acadêmicos e psicológicos a entrada de povos negros nas universidades. Ainda que os dados não se refiram diretamente aos discentes de pós-graduação em Rl, que é o interesse desse artigo, já dizem muito sobre quem seriam os estudantes em potencial para este nível de ensino. Se os estudantes negros não estão no nível da graduação, como chegariam à pós-graduação?

O vácuo de informação em relação ao perfil do discente da pós-graduação em RI dificulta o acesso a complexidade de tal tema, bem como informa o desinteresse por um estudo de tal escopo, reiterando a branquitude como norma. Uma vez que a raça branca é uma raça não nomeada e, portanto, naturalizada no Brasil como superior, não se postula a necessidade de delinear o perfil desses estudantes, já sabemos quem são eles. Ainda que tal pesquisa não tenha sido feita em Rl, a jornalista Lola Ferreira (2018), a partir dos dados do Censo da Educação Superior de 2016, traçou o perfil dos docentes com doutorado no Brasil.

Segundo tal estudo, o número de docentes doutores na pós-graduação no Brasil é de 53.995 professores, destes $24 \%$ (13.198) se declaram homens brancos, $19 \%(10.000)$ se declaram mulheres brancas, $0,4 \%$ (219) se declaram mulheres pretas. Se somadas, mulheres pretas e pardas compõem menos de $3 \%$ das doutoras na docência na pós-graduação no Brasil. Um problema deste estudo é a quantidade de docentes que não se autodeclaram. Entretanto, a própria não declaração já informa muito acerca da branquitude não nomeada na sociedade brasileira. Mesmo com o quanto número de docentes não declarantes, a composição da pós-graduação continua branca. Assim, as ações afirmativas no âmbito da graduação devem ser estendidas também na pós-graduação, contemplando

Disponível em: <http://portal.mec.gov.br/docman/agosto-2017-pdf/71071-produto-2-estudo-trajetoriaprofissionais-egressos-ri-pdf/files. Acesso em 07 de maio de 2019. 
estudantes negros e se tornando um incentivo maior para continuar a carreira academia.

A exemplo dos censos das décadas de 1960 e 1970, somente no ano de 2017 o Censo da Educação Superior começou a considerar a classificação racial como critério de amostragem. O CNPq, enquanto órgão de fomento à pesquisa cientifica no país, não considera no Lattes, maior plataforma de currículos no âmbito da academia, a classificação por raça (FERREIRA, 2018). Uma vez mais, a branquitude como estrutura das relações sociais no Brasil operacionaliza as ferramentas que podem ser usadas em benefício da população negra a seu favor. Sem a existência das classificações raciais no que condiz a produção acadêmica no Brasil, o perfil dos discentes e o fomento à pesquisa, é impossível pensar em medidas de reparação para que a população negra tenha acesso a essas instâncias de poder.

\section{Considerações Finais}

Este trabalho buscou, por meio de uma lente decolonial em perspectiva afrodiaspórica, chamar atenção para aspectos da sociedade brasileira que fazem parte da construção do curso de Relações Internacionais no Brasil: a branquitude como norma estruturante da sociedade, que posiciona a raça branca como uma raça não nomeada e, portanto, naturalizada e normalizada, enquanto povos não-brancos sofrem diversos tipos de exclusões políticas, econômicas e sociais. Também se atentou à violência e racismo epistêmico, que se traduz em negação da capacidade de sujeitas e sujeitos negros em produzir conhecimento, uma vez que esses sujeitos são desumanizados, e irracionalizados. Com isso, o epistemicídio de saberes negros e ancestrais é constantemente negado ou diminuído a categorias de achismos ou experiências, desautorizados em sua capacidade de explicar as relações políticas, econômicas e sociais. Além disso, a colonialidade foi explicitada como mecanismo de poder que permeia as relações entre povos brancos e não-brancos no Brasil.

O contexto brasileiro do governo militar, entre 1964 e 1985, moldou as RI como estudamos hoje. A repressão contra negros no país não é datada da ditadura, 
mas histórica desde o período colonial, atravessando gerações e presente até hoje. Nesse sentido, não é à toa que as demandas e proposições por movimentos sociais e intelectuais negros não sejam ouvidas durante o regime militar. Contudo, se nas décadas do regime militar, pós-abolição formal da escravidão e com as constantes demandas dos movimentos negros por acesso à população negra no Brasil, era criticável a exclusão e silenciamento de sujeitas e sujeitos negros, hoje, passados mais de trina anos do fim da ditadura e quarenta e cinco anos da formação do primeiro curso em RI, é inaceitável o silêncio em torno das violências invisibilizadas na sociedade como um todo e nas RI como disciplina que respondia a interesses de internacionalização de ideais brasileiros.

O epistemicídio recorrente de conhecimentos dos povos africanos e afrodiaspóricos reitera não só a branquitude como norma social, política, econômica e acadêmica, mas também a incessante pretensão por uma falsa universalidade da ciência moderna. As RI no contexto da modernidade recuperam os ideais universais típicos do iluminismo e abstrai problemas reais para os atores no sistema internacional, nem todos os problemas dos Estados giram ao redor da soberania ou interesse nacional. Conquista, colonialismo, colonialidade, escravidão, racismo são problemas internacionais invisibilizados pelas $\mathrm{RI}$, e não tratados como fundantes da própria conformação do Estado-nação.

Neste cenário, faz-se importante a continuação desta pesquisa no que condiz a dimensão epistemológica do ensino de RI no Brasil, impulsionando respostas a questionamentos como: Quem são os autores estudados? Quais assuntos abordados? Bem como nos Estados Unidos (KRISHNA, 2006), as RI no Brasil convergem em torno de categorias abstratas? O que foi silenciado entre os debates acerca do internacional para a construção da RI como estudamos hoje? Insta salientar que a negação epistemológica de um saber afrodiaspórico, epistemicídio, pode limitar a compreensão do internacional, assim como constranger as possibilidades de estudo de sujeitas e sujeitos negros, afinal, como visto nas seções anteriores, não são essas pessoas que majoritariamente compõe as salas de aula das universidades. Dessa forma, tangenciando os conceitos de colonialidade do poder e saber, em conjunto à colonialidade do ser, como ferramentas analíticas que possibilitam a leitura da colonialidade do conhecimento no ensino e pesquisa das RI, 
infiro que a branquitude como estrutura delimita quem pode ou não ter acesso ao conhecimento, bem como qual conhecimento será ensinado ou pesquisado.

Portanto, reivindico aqui a maior atenção das abordagens em Relações Internacionais para a potência do pensamento afrodiaspórico em relação a problemas reais em âmbito global. Chamar atenção para as fundações da disciplina calcadas em um racismo estrutural, institucional e epistêmico não é desqualificar suas proposições e sucessos, mas estender seu potencial crítico no sentido de transversalizar raça em seus debates. A inclusão de autores e autoras negras no estudo das RI e perspectivas negras sobre esse saber se mostra cada vez mais urgente, mas não suficiente por si só. O desafio está sempre em compreender que raça como categoria social inventada pela branquitude conforma toda a construção do saber na ciência moderna e como isso deve ser mobilizado no caminho de resgatar conhecimentos obliterados e reconhecer que nenhum saber é universal.

\section{Referências Bibliográficas}

ALMEIDA, M. A. B. D.; SANCHEZ, L. Os negros na legislação educacional e educação formal no Brasil. Revista Eletrônica de Educação, v. 10, n. 2, p. 234-246, 2016.

BALLESTRIN, L. América Latina e o giro decolonial. Revista Brasileira de Ciência Política, Brasília, n. 11, p. 89-117, 2013.

BENTO, M. A. S. Branqueamento e branquitude no Brasil. In: BENTO, M. A. S.; CARONE, I. Psicologia social do racismo - estudos sobre branquitude $e$ branqueamento no Brasil. Petrópolis: Vozes, 2002. p. 25-28.

BENTO, M. A. D. S. Notas sobre a expressão da branquitude nas instituições. In: BENTO, M. A. D. S.; SILVEIRA, M. D. J. S.; NOGUEIRA, S. G. Identidade, branquitude e negritude: Contribuições para psicologia social no Brasil: novos ensaios. relatos de experiência e de pesquisa. São Paulo: Casa do Psicólogo, 2014. p. 13-34.

CAPES. Programa San Tiago Dantas de apoio ao ensino de relações internacionais. Capes, [2001] 2008. Disponível em: <http://www.capes.gov.br/pt/bolsas/programasestrategicos/programas-estrategicos-encerrados/san-tiago-dantas>. Acesso em: 30 junho 2019. 
CAPES. Plataforma Sucupira, $2018 . \quad$ Disponível em: $<$ https://dadosabertos.capes.gov.br/dataset/coleta-de-dados-programas-da-posgraduacao-stricto-sensu-no-brasil-2017>. Acesso em: 30 junho 2019.

CASTRO-GÓMEZ, S. Ciências Sociais, violência epistêmica e o problema da "invenção do outro". In: LANDER, E. A colonialidade do saber: eurocentrismo e ciências sociais. Perspectivas latino-americanas. Buenos Aires: CLACSO, 2005. p. 80-87.

DUSSEL, E. Meditaciones anti-cartesianas: sobre el origen del anti-discurso filosófico de la Modernidade. Tabula Rasa, n. 9, p. 153-197, 2008.

FANON, F. Os condenados da Terra. Civilização Brasileira: Rio de Janeiro, 1979.

FANON, F. Pele negra, máscaras brancas. Salvador: EDFBA, 2008.

FERNANDES, F. A integração do negro na sociedade de classes: no limiar de uma nova era. São Paulo: Globo Livros, 2008.

FERREIRA, L. Menos de 3\% entre docentes da pós-graduação, doutoras negras desafiam o racismo na academia. GêneroNúmero, 2018. Disponível em: $<$ http://www.generonumero.media/menos-de-3-entre-docentes-doutoras-negrasdesafiam-racismo-na-academia/>. Acesso em: 31 outubro 2019.

FERREIRA, M. A. S. V. The Rise of International Relations Programs in the Brazilian Federal Universities: Curriculum Specificities and Current Challenges. Journal of Political Science Education, v. 12, n. 3, p. 241-255, 2015.

FOUCAULT, M. Vigiar e Punir: o nascimento da prisão. Petrópolis: Vozes, 1987.

GOMES, A. C. D. B. Colonialidade na academia jurídica brasileira: uma leitura decolonial em perspectiva amefricana. Tese de doutorado (Doutorado em Direito) Programa de Pós-Graduação em Direito - PUC-Rio. Rio de Janeiro. 2019.

GONZALEZ, L. Racismo e sexismo na cultura brasileira. Revista Ciências Sociais Hoje, p. 223-244, 1984.

GONZALEZ, L. A categoria político-cultural de amefricanidade. Tempo Brasileiro, v. 92, n. 93, p. 68-92, 1988.

GROSFOGUEL, R. A estrutura do conhecimento nas universidades ocidentalizadas: racismo/sexismo epistêmico e os quatro genocídios/epistemicídios do longo século XVI. Revista Sociedade e Estado, v. 31, n. 1, p. 25-49, 2016.

HARAWAY, D. Saberes Localizados: a questão da ciência para o feminismo e o privilégio da perspectiva parcial. Cadernos Pagu, v. 5, p. 07-41, 1995.

JONES, B. G. International Relations, Eurocentrism, and Imperialism. In: JONES, B. G. Decolonizing International Relations. Plymouth: Rowman \& Littefield Publishers, 2006. p. 1-22. 
JULIÃO, T. S. A graduação em Relações Internacionais no Brasil. Monções: revista de Relações Internacionais da UFGD, v. 1, n. 1, p. 13-48, 2012.

KRISHNA, S. Race, amnesia, and the education of international relations. In: JONES, B. G. Decolonizing International Relation. Maryland: Rowman \& Littlefield, 2006.

LAFER, C. O estudo das relações internacionais: necessidade e perspectivas (1982). In: LAFER, C. Relações Internacionais, política externa e diplomacia brasileira: pensamento e ação. Brasília: FUNAG, 2018. p. 327-342.

LANDER, E. ¿Conocimiento para qué? ¿Conocimiento para quién? Reflexiones sobre la universidad y la geopolítica de los saberes hegemónicos. Estudios Latinoamericanos, v. 7, n. 12-13, p. 26-46, 2000.

MALDONADO-TORRES, N. A topologia do ser e a geopolítica do conhecimento. Modernidade, império e colonialidade. Revista Crítica de Ciências Sociais, v. 80, p. 71-114, 2008.

MBEMBE, A. Crítica da Razão Negra. Lisboa: Antígona, 2014.

MIGNOLO, W. Espacios geográficos y localizaciones epistemológicas: la ratio entre la localización geográfica y la subalternización de conocimientos. GEOgraphia, v. 7, 1996.

MIGNOLO, W. Postoccidentalismo: el argumento desde América Latina. In: CASTRO-GÓMEZ, S.; MENDIETA, E. Teorías sin disciplina: latinoamericanismo, poscolonialidad y globalización en debate. México: Miguel Ángel Porrúa, 1998.

MIGNOLO, W. The geopolitics of knowledge and the colonial difference. The South Atlantic Quarterly, v. 101, n. 1, p. 57-95, 2002.

MIGNOLO, W. Desobediencia epistémica: Retórica de la modernidaa, lógica de la colonialidad y gramatica de la descolonialidad. Buenos Aires: Ediciones del Signo, 2010.

MIRANDA, C. Narrativas Subalternas e Políticas de Branquidade: O Deslocamento de Afrodescendentes como Processo Subversivo e as Estratégias de Negociação na Academia. Tese de doutorado (Doutorando em Educação) - Programa de PósGraduação em Educação/Proped - UERJ. Rio de Janeiro. 2006.

MIYAMOTO, S. O Estudo das Relações Internacionais no Brasil: o estado da arte. Revista de Sociologia e Política, n. 12, p. 83-98, 1999.

MIYAMOTO, S. O ensino das relações internacionais no Brasil: problemas e perspectivas. Revista de Sociologia Política, n. 20, p. 103-114, junho 2003.

NASCIMENTO, A. D. O quilombismo. Rio de Janeiro: Vozes, 1980. 
NASCIMENTO, A. D. O genocídio do negro brasileiro: processo de racismo mascarado. São Paulo: Perspectiva SA, 2016.

PASSOS, J. C. D. As desigualdades na escolarização da população negra e a Educação de jovens e Adultos. ELA EM DEBATE, v. 1, n. 1, p. 137-158, 2012.

PIRES, T. R. D. O. Estruturas Intocadas: Racismo e Ditadura no Rio de Janeiro. Direito e Práxis, v. 9, n. 2, p. 1054-1079, 2018.

QUIJANO, A. Colonialidad de Poder y Clasificacion Social. Journal of World-Systems Research, v. 11, n. 2, p. 342-386, 2000.

SANDOVAL, C. Methodology of the Opressed. Minneapolis: University of Minnesota, 2000.

SANTOS, B. D. S.; MENEZES, M. P. Epistemologias do Sul. São Paulo: Cortez, 2010.

SMITH, L. T. Decolonizing Methodologies: research and indigeneous people. London: Zed Books, 2012.

VIGEVANI, T.; THOMAZ, L. F.; LEITE, L. A. B. Pós-graduação em Relações Internacionais no Brasil: Anotações sobre sua institucionalização. Revista Brasileira de Ciências Sociais, v. 31, n. 91, p. 1-31, 2016.

VITALIS, R. White world order, black power politics: The birth of American international relations. New York: Cornell University Press, 2015. 